\title{
Imunidade antitruste às Ações Governamentais no contexto da desregulação do setor de telecomunicações: uma análise a partir do julgamento do caso VU-M pelo CADE
}

State Action Antitrust Exemption in a Context of Deregulation of the Telecommunications Sector: An Analysis of CADE's VU-M Case

\section{RESUMO}

Propósito - O objetivo deste ensaio é examinar a postura adotada pelo CADE com relação às medidas regulatórias adotadas pela ANATEL na fixação do valor de interconexão de rede (VU-M), sob a perspectiva da State Action Doctrine no contexto da desregulação do setor de telecomunicações.

Metodologia/abordagem/design - $\mathrm{O}$ texto propõe uma abordagem relativa às teorias de desregulação do setor de telecomunicações e o impacto que as decisões da autoridade antitruste de isenção concorrencial possuem neste movimento, a partir da análise do caso VU-M recentemente julgado pelo CADE.

Resultados - A concessão de isenções antitruste pelo CADE ainda parece seguir a tradicional aplicação da State Action Doctrine centrada na teoria regulatória do interesse público e, consequentemente, a extrema confiança na atuação da agência acaba dificultando o processo de desregulação, principalmente no setor de telecomunicações, notadamente marcado pela antiga estrutura regulatória oligopolista.

Implicações práticas - Busca-se, por meio desta análise crítica, oferecer uma abordagem introdutória que possa ser aplicada posteriormente para rediscutir os limites de aplicação da lei de defesa da concorrência a situações acobertadas por medidas regulatórias setoriais.

Originalidade/relevância do texto - $\mathrm{O}$ ensaio identifica os elementos que se aplicam na dinâmica de interação entre regulação concorrencial e a regulação setorial, a ponto de permitir que a tradicional estrutura de aplicação das normas de concorrência a estes setores possa ser redesenhada para incorporar os objetivos

*Mestranda em Direito, Estado e Constituição pela Universidade de Brasília. Bacharela pelo Centro Universitário de Brasília. Desde 2002, é servidora do Conselho Administrativo de Defesa Econômica (CADE). Contato: deborah.caixeta@gmail.com. 
perseguidos pelo movimento de desregulação, no caso, do setor de telecomunicações.

Palavras-chave: state action, desregulação, antitruste, telecomunicações, VU-M.

\begin{abstract}
Purpose - The purpose of this essay is to examine CADE's behavior in relation to regulatory measures adopted by ANATEL in fixing the mobile interconnection rate (Portuguese acronym VU-M), from the perspective of the State Action Doctrine in the context of deregulation of the telecommunications industry in Brazil.

Methodology/approach/design - The paper presents an approach to the theories of deregulation of telecommunications industry and the impact that antitrust exemptions have on this movement from the perspective of the VU-M Case recently ruled by $C A D E$.

Findings - The granting of antitrust exemptions by CADE still seems to follow the traditional application of the State Action Doctrine focused on regulatory theory of public interest and, therefore, the utmost confidence in the performance of the agency ends up hindering the process of deregulation, particularly in the telecommunications industry, characterized by the traditional oligopolistic regulatory structure.

Practical implications - This review provides an introductory approach that can be applied later to revisit the limits of application of antitrust law to situations covered up by sectorial regulatory measures.

Originality/value - This essay points to elements that can be applied in the dynamic interaction between sectorial regulation and competition regulation. This approach allows the traditional structure of application of competition rules to regulated sector to be redesigned to incorporate the objectives pursued by the movement of deregulation in telecommunications industry.
\end{abstract}

Keywords: state action, deregulation, antitrust, telecommunication, VU-M

\title{
1. Introdução
}

O escopo do trabalho consiste em reavaliar a interação entre a autoridade antitruste federal - o Conselho Administrativo de Defesa Econômica (CADE) - e outros entes governamentais, o que, sob aspectos histórico-institucionais, vem sofrendo limitações, principalmente, em razão 
das implicações da State Action Doctrine e do papel que o Estado assume na regulação de setores da economia.

A análise tem como ponto de partida a recente decisão tomada pelo CADE no âmbito de processo administrativo instaurado contra as empresas de telecomunicações - TIM, VIVO, CLARO e OI - que supostamente estariam restringindo a concorrência no mercado por meio de duas condutas anticompetitivas: a) elevação dos custos dos rivais, consubstanciada na cobrança, por parte das empresas de telefonia móvel, de preços públicos para a terminação de chamadas intra-rede com valores bem inferiores aos cobrados pelo Valor de Remuneração do Uso da Rede Móvel (VU-M) e b) suposto conluio entre elas para a fixação dos valores do VU-M.

Segundo os termos da representação que deflagrou a instauração do processo, os indícios de infração concorrencial apontados são reforçados principalmente diante do fato de que, a partir de 2004, a Agência Nacional de Telecomunicações (ANATEL) suspendeu a regulação da tarifa VU-M, passando, desde então, a ser um componente de livre pactuação entre as empresas interessadas.

No entanto, verificou-se ao longo da instrução do processo, que o insucesso na livre negociação da tarifa levou a fixação, pela própria ANATEL, de um único reajuste do VU-M, o qual foi seguido e aplicado em seu valor máximo por todas as empresas de telefonia móvel.

$\mathrm{Na}$ ocasião do julgamento do referido processo pelo CADE, a Conselheira-Relatora, Ana Frazão, reconheceu a natureza exclusivamente regulatória da questão e afastou a incidência da regulação concorrencial sob o argumento de que "a partir do momento em que os valores de VU-M foram fixados ou referendados pela ANATEL, não há espaço para a prática de abuso de poder econômico pelas Representadas".

A decisão proferida no caso pode levar à conclusão de que os mecanismos regulatórios adotados pela ANATEL, com relação a fixação da tarifa de VU-M para prevenir abusos no processo competitivo em questão está, igualmente, distorcendo essa concorrência, levando a um processo definido por Harry First como "regulated deregulation".

Assim, neste contexto de isenções antitruste e "desregulação regulada" do setor de telecomunicações, conferir maior deferência a políticas regulatórias combinada a uma ampla aplicação de imunidades antitrustes a 
condutas respaldadas por ações governamentais poderia favorecer a manutenção das velhas estruturas regulatórias, onde as empresas reguladas podem capturar os interesses da agência regulatória, dificultando o próprio processo de desregulação do setor.

Desta forma, a análise requer, primeiramente, compreender em que circunstâncias foi proferida a decisão do CADE, a fim de verificar se se trata de uma isenção antitruste respaldada pela State Action Doctrine. Essa análise requer, igualmente, verificar a própria natureza da State Action Doctrine e a sua correlação histórica com as teorias regulatórias - que procuram explicar a intervenção governamental nas relações econômicas como fontes legitimadoras da isenção antitruste.

Por fim, busca-se estabelecer parâmetros conceituais de aproximação entre o movimento de desregulação do setor de telecomunicações e a aplicação da State Action Doctrine, a fim de verificar se a aplicação da isenção antitruste pode afetar negativamente os objetivos perquiridos por aquela nova teoria da regulação econômica. A partir de então, o trabalho procura traçar um ponto de partida para se verificar se seria possível a autoridade antitruste atuar sobre esse fenômeno de "desregulação regulada" a fim de estabelecer novamente a livre concorrência e a corrigir os efeitos anticompetitivos causados por medidas implementadas pelas agências regulatórias.

\section{O caso VU-M}

Em 2007, a empresa Global Village Telecom Ltda. (“GVT”) apresentou ao Sistema Brasileiro de Defesa da Concorrência representação contra as empresas de telefonia móvel do Brasil - TIM, VIVO, Claro e OI - em que alegava estar sofrendo discriminação por parte dessas empresas no acesso à rede de terminação de chamadas, pois as empresas de telefonia móvel estariam cobrando altos valores de VU-M ao passo que conseguem ofertar preços públicos para chamadas móvel-móvel (on-net) bastante inferiores, o que, segundo a representante, seriam prejudiciais à concorrência e afetariam, de forma significativa as operadoras de telefonia fixa sem braços móveis.

Além disso, destacou a representante GVT que os indícios anticompetitivos eram ainda mais evidentes uma vez que o valor de VU-M 
já não era objeto de regulação por parte da ANATEL, de modo que as representadas estariam abusando dessa liberdade por meio da imposição de preços excessivos para o término de chamadas em suas respectivas redes.

Nos termos da representação, a conduta das representadas estaria limitando o acesso das empresas de telefonia fixa a um insumo essencial que permite a entrada e consolidação daquelas empresas no mercado de telefonia. Segundo a GVT, as redes de interconexão podem ser consideradas essential facility, por duas razões: (i) para sobreviver no mercado de telefonia, as empresas de telefonia fixa devem necessariamente oferecer chamadas para os usuários das operadoras de telefonia móvel e (ii) cada operadora móvel detém o monopólio para a interconexão do término de chamadas na sua própria rede.

Os argumentos da representante buscaram amparo nas disposições da própria Lei Geral de Telecomunicações - LGT (Lei 9.472/97), a qual estabelece, em seu art. 152, que a interconexão deve ser provida para atender estritamente ao necessário a prestação do serviço, o que significa que o seu valor deveria se ater ao valor dos custos da operação de transporte da chamada na rede. Daí, ao comparar os valores que remuneram o uso da rede móvel e os de uso da rede fixa, a GVT concluiu que os valores de VU$\mathrm{M}$ eram excessivos, pois, enquanto o valor de uso da rede fixa era de $\mathrm{R} \$$ 0,03, o VU-M cobrado pelas operadoras móveis era de cerca de $\mathrm{R} \$ 0,40$.

As preocupações tecidas pela GVT foram, inclusive, confirmadas pela Secretaria de Direito Econômico (SDE) que, ao analisar os dados fornecidos tanto pela ANATEL como pelas empresas representadas com relação ao custo marginal de uso das redes fixas e móveis, verificou que a taxa de VUM está muito acima do custo marginal da rede móvel, o que, segundo a Secretaria, geraria, no longo prazo, prejuízos à concorrência na medida em que possibilitaria a extinção de empresas de telefonia fixa.

Além da diferença de preço entre rede fixa e móvel, a GVT alega que os preços de público das empresas de telefonia móvel são bastante inferiores ao valor da tarifa VU-M, o que seria uma inconsistência, já que os custos para estabelecer ambas as interconexões seriam os mesmos. Tal argumento foi também aceito pela SDE sob o fundamento de que "os custos incorridos na terminação de chamadas originadas em outra operadora e nela própria são praticamente os mesmos e que as operadoras de STFC precisam realizar 
ligações fixo-móvel". Assim, a Secretaria reconheceu este fato também como forte indício de abusividade e da prática de discriminação de concorrentes em relação a uma essential facility, uma vez que aumenta de forma artificial os custos das empresas de telefonia fixa.

A representante acrescentou ainda que quando se trata de operações móvel-móvel on-net (intra-rede), sequer há de falar em interconexão já que a operação ocorre na própria rede da operadora. Já nas chamadas móvelmóvel off-net (inter-redes) o VU-M não seria um problema, pois as operadoras móveis compensam entre si os respectivos valores. Essa estrutura, segundo a GVT, reforça o caráter prejudicial da diferença significativa entre os valores de uso das redes fixa e móvel já que não apenas dificulta a consolidação de empresas de telefonia fixa no mercado como um todo, como também impede a entrada de novos concorrentes no mercado de telefonia móvel. Nesta linha, como esclarecido pela SDE, a cobrança de altas taxas de interconexão, com o escopo de subsidiar os consumidores de telefonia móvel, tende a trazer mais prejuízos que benefícios ao mercado, uma vez que desestimula a originação de chamadas fixa, ao passo que direciona o consumidor a realizar chamadas para aparelhos conectados na mesma rede.

Aliás, tais preocupações não passaram despercebidas pelo Departamento de Estudos Econômicos do CADE, o qual verificou a existência de elementos no mercado atual que sinalizam para uma redução da taxa de uso da interconexão entre redes, tais como, incremento no uso de telefones celulares com dois chips e diferencial de preços entre chamadas on-net e off-net. Como observou o Departamento, "sob o ponto de vista concorrencial, tal situação se afasta do ideal, uma vez que ao incentivar ligações dentro de suas próprias redes tende a ocorrer uso menos eficiente do sistema interconectado" ${ }^{1}$.

No mesmo sentido a SDE, diante dos fatos apresentados, verificou os possíveis efeitos concorrenciais adversos da fixação da tarifa de VU-M, especialmente quando a Secretaria aponta (i) que o suposto alto custo da interconexão esteja gerando distorções, tais como a necessidade de que as

${ }^{1}$ Estudo do Departamento de Estudos Econômicos do CADE proferido nos autos do PA 08012.008501/2007-91. 
pessoas tenham vários chips, a fim de que façam ligações apenas intra-rede e (ii) que o Brasil é um dos países com as mais altas tarifas de telefonia celular do mundo, sendo que diferentes estudos apontam o VU-M como a principal causa de tal situação.

Na mesma linha desenhada pela Secretaria, o Ministério Público entendeu que da "análise de custo-benefício, percebe-se que os custos do alto valor do VU-M, decorrente do modelo de regulação, que acaba por permitir atuação anticompetititiva das Representadas, superam seus benefícios", opinando, assim, pela condenação das empresas representadas.

Já no julgamento do processo pelo CADE, não obstante as preocupações concorrenciais endereçadas ao longo da instrução, a análise empreendida pelo Conselho concentrou-se essencialmente no processo histórico de estipulação da tarifa VU-M para, ao fim, afastar a responsabilidade das empresas e arquivar o feito.

Até 2004, por meio da Resolução n ${ }^{\circ} 319$, de 27/09/2002, as tarifas de VU-M deveriam ser obrigatoriamente homologadas pela ANATEL, de forma que a agência exercia o controle regulatório ex ante do valor da tarifa. $^{2}$ Posteriormente, com o fim da vigência da referida resolução, a ANATEL abandonou o papel de controlador do reajuste da VU-M para assumir a posição de agente arbitrador, resolvendo eventuais desavenças na pactuação da tarifa, tal como expressamente disposto no $\S 2^{\circ}$, art. 153 da LGT:

Art. 153. As condições para a interconexão de redes serão objeto de livre negociação entre os interessados, mediante acordo, observado o disposto nesta Lei e nos termos da regulamentação.

$\S 1^{\circ} 0$ acordo será formalizado por contrato, cuja eficácia dependerá de homologação pela Agência, arquivando-se uma de suas vias na Biblioteca para consulta por qualquer interessado.

${ }^{2}$ Informe ANATEL $\mathrm{n}^{\circ}$ 81/2008, fls. 3192-3193 dos autos do PA $\mathrm{n}^{\circ}$ 08012.008501/2007. 
$\S 2^{\circ}$ Não havendo acordo entre os interessados, a Agência, por provocação de um deles, arbitrará as condições para a interconexão.

Ocorre que, como apontou a ANATEL, não houve acordo satisfatório entre as empresas de telefonia acerca do valor da tarifa VU-M, o que motivou a constituição, pela própria Agência, de uma Comissão de Arbitragem em Interconexão (CAI) destinada a discutir o preço pago pela referida tarifa de interconexão. Como forma de minorar os efeitos da delonga desse litígio, grande parte das empresas prestadoras de Serviço Telefônico Fixo Comutado (STFC) e Serviço Móvel Pessoal (SMP) assinaram inúmeros Pactos Provisórios, os quais definiam que o último valor de VU-M anteriormente homologado pela ANATEL sob o regime regulado seria reajustado no único percentual de 4,5\%. Ao fim, referidos pactos foram homologados pela ANATEL no referido processo de arbitragem.

A ANATEL esclareceu que embora estivesse prestigiando os princípios da autonomia da vontade e da livre pactuação do VU-M num primeiro momento, é certo que, na prática, o reajuste de 4,5\% estipulados de forma provisória pelas partes foi, ao final, determinado cautelarmente e reconhecido como adequado pela autoridade reguladora. Tanto é assim que, por meio de despacho, a ANATEL determinou o reajuste do VU-M no percentual de $4,5 \%$.

Desta forma, diante da expressa ratificação do reajuste de $4,5 \%$ pela ANATEL, o Conselho entendeu que não haveria qualquer responsabilidade a ser imputada às empresas representadas, já que o VU-M "não pode ser considerado como imposto unilateralmente pelas operadoras móveis ou como resultado espontâneo e natural do processo de negociação". 3

Nestas circunstâncias, entendeu a Relatora do processo que:

"0 pressuposto da existência de infração à concorrência é precisamente a existência de determinada margem de autonomia que a regulação deixe para os agentes econômicos. Se não há propriamente

${ }^{3}$ Voto da Conselheira-Relatora, Ana Frazão, no PA no 08012.008501/2007-91, p. 35. 
livre comportamento por parte desses agentes, não há como se lhes imputar conduta autônoma e, muito menos, conduta abusiva". ${ }^{4}$

Ou seja, na medida em que a autonomia do agente econômico é afastada por ato regulatório, não há que se falar na possibilidade de infração à ordem econômica já que o agente estará atuando dentro e nos limites dos comandos impostos pela autoridade reguladora. E, assim, concluiu:

"se existe algum problema relacionado ao VU-M, esse problema é, nas circunstâncias delineadas no presente feito, essencialmente regulatório. Se há distorções à concorrência, decorrem elas do âmago da política regulatória que vem sendo implementada pela ANATEL".

Desta forma, a atuação direta da ANATEL na determinação do valor do VU-M foi considerada pelo Conselho, não obstante outros fundamentos apresentados, como fator suficiente para afastar a incidência do direito concorrencial naquele caso.

\section{State Action Doctrine e a sua correlação com as teorias da regulação econômica}

A articulação entre regulação setorial e regulação concorrencial sempre foi objeto de muita controvérsia - e ainda é -, havendo sempre espaço para o amadurecimento e consolidação do tema.

Nos Estados Unidos, duas teorias foram desenvolvidas para tratar do aparente conflito entre as duas formas de regulação. A primeira, State Action Doctrine ou Teoria do Ato Político, foi desenvolvida para tratar da questão sob o aspecto do federalismo, ou seja, da relação entre atos regulatórios estaduais e a lei federal antitruste. A segunda, Pervasive Power Doctrine ou Teoria do Amplo Poder, trata propriamente da regulação setorial e a regulação concorrencial no âmbito do poder executivo federal. Esta última, na verdade, é uma adaptação da própria Teoria do Ato Político a questões que não envolvem necessariamente o conflito federativo

${ }^{4}$ Idem, p. 36.

${ }^{5}$ Ibid., p. 37. 
(Marques Neto, 2002, p. 104), ou seja, são teorias que se amparam sob o mesmo substrato. Consequentemente, será dado enfoque ao desenvolvimento da State Action Doctrine - já que se trata da teoria originária - e a sua relação com as teorias regulatórias para apontar os elementos que inicialmente interferiram na relação entre a regulação setorial e geral ${ }^{6}$, no caso, a regulação concorrencial.

O primeiro registro de aplicação da State Action Doctrine nos Estados Unidos foi no caso Parker v. Brown de 1943 em que a representante Brown insurgiu-se contra um programa do governo estadual de controle obrigatório das condições de comercialização de certos produtos agrícolas, em especial, o preço de venda. Naquele julgamento, a Suprema Corte entendeu que mesmo admitindo que na ausência do ato governamental, a situação contestada seria de fato uma violação antitruste $^{7}-$, ante a ausência de competência expressa no Sherman Act para atuar sobre atos oficiais, aquela conduta estaria imune a atuação antitruste.

Ao analisar o momento histórico em que a decisão no caso Parker $v$. Brown foi proferida, Delacourt e Zywicki (2005) verificaram que elementos da teoria regulatória do interesse público influenciaram de forma determinante a Suprema Corte. Havia um extremo ceticismo quanto às forças do mercado e a necessidade inafastável da atuação do governo para proteger o público dos efeitos nefastos de uma competição desenfreada, isto é, uma crença de que a regulação é a única forma de atender a demanda do público para corrigir condutas no setor econômico que são ineficientes e injustas (Posner, 1974).

A incontestável crença na capacidade regulatória do Estado daquele momento pode ser associada à fase Progressiva da Teoria do Interesse Público descrita por Horwitz (1989, p. 25). Segundo o autor, as primeiras

${ }^{6}$ Para as diferenças entre regulação geral e setorial vide SALOMÃO FILHO, Calixto. Regulaçã̃o da atividade econốmica: princípios e fundamentos jurídicos. $2^{a}$ ed., São Paulo: Malheiros, 2008, p. 37.

${ }^{7}$ Trecho da decisão em Parker vs. Brown em que o juiz admite a violação da lei antitruste caso a conduta fosse resultado da autonomia de entes privados: "We may assume for present purposes that the California prorate program would violate the Sherman Act if it were organized and made effective solely by virtue of a contract, combination or conspiracy of private persons, individual or corporate". Disponível em: http://supreme.justia.com/cases/federal/us/317/341/case.html.

Revista de Direito, Estado e Telecomunicações, v. 6, n. 1, p. 127-158 (2014)

DOI: https://doi.org/10.26512/lstr.v6i1.21555 
décadas do século XX foram marcadas por uma ideologia econômica centrada na eficiência da produção e na proteção do consumidor, em que a regulação atuava necessariamente para controlar as concentrações empresariais e para promover o bem-estar geral do elo mais fraco da cadeia produtiva. Isso significa que, uma vez que as agências reguladoras foram criadas com o propósito de promover a estabilidade do mercado, havia uma credibilidade, inquestionável, na regularidade de seus atos e na sua capacidade de atender ao bem-estar geral.

Esse aspecto da Teoria do Interesse Público pode ser visualizado em trechos da decisão no caso Parker v. Brown:

"A prorate marketing program under the California Agricultural Prorate Act, adopted by the State for regulating the handling, disposition, and prices of raisins produced in California, a large part of which go into interstate and foreign commerce, held not within the intended scope of, and not a violation of, the Sherman Act.

\section{(...)}

The marketing program for the 1940 raisin crop, adopted pursuant to the California Agricultural Prorate Act, the declared purpose of which is to "conserve the agricultural wealth of the State" and to "prevent economic waste in the marketing of agricultural products" of the State, and which operates to eliminate competition among producers in respect of the terms of sale (including the price) of the crop and to impose restrictions on the sale and distribution to buyers who subsequently sell and ship in interstate commerce, held a regulation of state industry of local concern which, in the circumstances detailed in the opinion, is not prohibited by the commerce clause in the absence of Congressional legislation prohibiting or regulating transactions affected by the state program.

(...)

But it is plain that the prorate program here was never intended to operate by force of individual agreement or combination. It derived its authority and its efficacy from the legislative command of the state, and was not intended to operate or become effective without that command. We find nothing in the language of the Sherman Act or in its history which suggests that its purpose was to restrain a state or its officers or agents from activities directed by its legislature. The Sherman Act makes no mention of the state as such, and gives no hint that it was intended to restrain state action or official action directed by a state. The Act is 
applicable to "persons," including corporations ( § 7), and it authorizes suits under it by persons and corporations ( $\$ 15) . "{ }^{\prime \prime}$

Vê-se, desta forma, no que tange a aplicação de isenções antitruste, uma generalização no emprego de rótulos como "público", "oficial", "governamental", um tipo de análise sumária que sequer procura avaliar as reais circunstâncias em que o ato regulatório foi proferido e se o agente investigado tinha autonomia para adotar uma postura distinta daquela permitida pelo Estado. Da mesma forma, observa-se certa ignorância quanto aos próprios propósitos da política regulatória, na medida em que o Tribunal estaria disposto a conferir o benefício da dúvida ao ato regulatório sem ao menos questionar se a política regulatória poderia ter assumido alguma forma menos restritiva a concorrência para alcançar os mesmos fins.

A decisão em Parker v. Brown é bastante elucidativa neste aspecto na medida em que deixa ressaltar uma aparente convicção de que as agências reguladoras foram criadas para empregar o poder positivo do estado a fim de retirar vantagens das eficiências econômicas e de servir ao bem-estar geral, e, assim o fazendo, protegeria os consumidores dos abusos das corporações privadas.

Outro caso paradigmático que contribuiu para o desenho da State Action Doctrine foi o julgamento do conflito entre California Retail Liquor Dealers Association v. Midcal Aluminum, Inc.. Neste caso, a Corte esclareceu importantes parâmetros da imunidade concorrencial ao decidir que estariam isentas as entidades privadas que (i) estivessem atuando em conformidade com uma política estatal claramente articulada (clearlyarticulated) e (ii) que estivessem constantemente supervisionadas pelo poder público.

Nota-se, a partir de então, um novo movimento de aplicação de isenções antitrustes resultante de alterações visualizadas no papel do governo, a partir de uma visão cínica da atividade estatal, a qual - tal como os entes privados -, também possuía interesses econômicos próprios.

${ }^{8}$ U.S. Supreme Court. Parker v. Brown, 317 U.S. 341 (1943) de 4 de janeiro de 1943. Disponível em: http://supreme.justia.com/cases/federal/us/317/341/case.html. 
O ceticismo em relação ao papel do governo passou a desempenhar um papel dominante nas teorias econômica e política, as quais reclamavam mais pesquisas empíricas à respeito do que seriam e como agiam os "grupos de interesses". Consequentemente, os trabalhos inicias desenvolvidos com o intuito de apontar as lacunas da Teoria do Interesse Público formaram o substrato para um ponto de vista alternativo que veio a ser conhecida como Teoria da "Escolha Pública" ou Teoria da Public Choice.

Primeiramente, havia certa consciência de que, na realidade, algumas agências reguladoras foram criadas não em resposta a clamores democráticos de um público oprimido, mas sim em resposta a demandas específicas do setor industrial por proteção e subsídios (Horwitz 1989, p. 27). Em segundo lugar, a teoria do interesse público desconsidera a estrutura da economia e da formação do poder econômico, e, consequentemente, a definição de interesse público geralmente não leva em consideração as reais práticas e objetivos perseguidos pela agência reguladora, já que, como afirma Horwitz (1989, p. 26), a maior parte da regulamentação visa a beneficiar a indústria e facilitar o comércio.

A teoria, na verdade, procurava estabelecer uma analogia do processo de tomada de decisão regulatória com o processo de alocação econômica, tratando instituições legislativas, regulatórias e institucionais como uma economia, em que legisladores, agências e grupos de interesses pudessem trocar "bens regulatórios", os quais são ofertados e demandados de acordo com os mesmos princípios básicos que regem a oferta/demanda econômica (Croley, 2008, p. 19).

A nova teoria buscou, desta forma, introduzir uma nova metodologia para avaliar a correlação entre a conduta anticompetitiva e a política governamental desenhada para aquele setor, numa tentativa de identificar as consequências que estariam especificadamente resguardadas por determinações do poder público. Isso significa que o fundamento de aplicação da State Action Doctrine não repousava mais na crença inabalável do "bom governo", como o era no caso Parker, mas numa avaliação realista dos incentivos que regiam o processo de tomada de decisão pelo órgão governamental.

Contraditoriamente, em termos práticos, a sua aplicação ainda refletia o entendimento pretérito a respeito da aplicação da isenção antitruste. 
Segundo os termos da decisão proferida no caso Midcal, não haveria a necessidade de qualquer orientação expressa do ato regulatório em substituir a competição em determinado segmento, mas estariam igualmente amparados pela isenção antitruste qualquer resultado anticompetitivo meramente previsível a partir do ato regulatório (forseeable result). Isto é, não havia a necessidade de uma determinação expressa para aquele ato anticompetitivo, mas tão somente que a conduta possivelmente estivesse dentro dos propósitos perseguidos pela política da agência reguladora. ${ }^{9}$

Essa interpretação ainda traduzia uma confiança indiscriminada no poder das agências regulatórias. ${ }^{10}$ Ao invés de perquirir os reais interesses que a agência regulatória possuía para autorizar um ato anticompetitivo - e em que medida estes incentivos estavam de acordo com as determinações legais para o setor - a Corte Americana simplesmente averiguava a natureza do órgão emissor da autorização se "público" ou "governamental". ${ }^{11} \mathrm{Ou}$

${ }^{9} \mathrm{Tal}$ entendimento pode gerar certos inconvenientes quando o propósito da agência reguladora não for claramente estabelecido por um ato normativo. No julgamento do caso Ticor pela Corte Norte-americana (caso em que se verificou alegações de que seis das maiores companhias de seguros de título da nação haviam conspirado para fixar preços em buscas de títulos e exames de títulos), por exemplo, o Tribunal observou que a proteção a ação do Estado (isenção antitruste) é "conferida por respeito a regulação contínua do Estado, não por respeito a economia de contenção de preços." E assim reconheceu não só a possibilidade de que os esforços de fiscalização do Estado poderiam ser insuficientes, mas que essa inadequação poderia refletir um motivo impróprio (ou seja, o desejo de perseguir "contenção de preço" para um propósito não-regulatório). Então, o simples fato de um mercado ser historicamente marcado pela regulação, não significa que a agência regulatória esteja perseguindo os objetivos inicialmente traçados quando se determinou a regulação daquele setor.

${ }^{10}$ Office of Policy Planning, Federal Trade Commission, Report of the State Action Task Force 25-36 (Sept. 2003) [FTC State Action Report]. Disponível em: http://www.ftc.gov/os/2003/09/stateactionreport.pdf. Acesso em: 05 de outubro de 2013.

11"Autorização" no contexto da imunidade antitruste da ação do Estado tem dois significados. $\mathrm{O}$ primeiro é a autoridade da agência regulatória para fazer o ato. $\mathrm{O}$ segundo é a intenção do Estado em permitir ao agente econômico agir de forma anticompetitiva e, portanto, para deslocar as leis antitruste. A maioria dos tribunais norte-americanos entendem que declarar esta autorização significa claramente que 0 legislador contemplou a aprovação de uma ação que, se vista de outra forma, violaria as leis antitruste, mas decidiu autorizá-la de qualquer maneira. Utilizam, desta 
seja, assim como no caso Parker vs. Brown, para a concessão de imunidade antitruste verificava-se tão somente a presença do status público da entidade que autorizou o ato - a qual, presumivelmente, atuava em nome do interesse público -, o que poderia levar a um entendimento equivocado sobre os reais objetivos perseguidos pelo Estado e a sua conexão com a conduta do agente infrator (Delacourt, 2005).

Posteriormente, as decisões da Corte americana ainda refletiam uma a contínua tendência em direção a uma abordagem orientada pela Teoria da Escolha Pública na medida em que buscavam aperfeiçoar os pressupostos da isenção antitruste anteriormente fixados no julgamento do caso Midcal.

No caso Columbia Steel Casting Co. v. Portland General Electric Co., ${ }^{12}$ por exemplo, para que uma conduta anticompetitiva seja blindada com imunidade antitruste, ela deve ser um resultado previsível de uma política pública devidamente autorizada, isto é, a política regulatória deve ser específica no sentido de admitir a conduta anticompetitiva em questão. Além disso, o teste de aplicação da isenção deve centrar-se na conduta em si e não no esquema regulatório responsável por supervisioná-la.

Daí a necessidade de se incluir dentre os requisitos para a imunidade, não somente a opção expressa do legislador pela regulação e a supervisão constante do comportamento do administrado pela agência reguladora, mas também previsão expressa no sentido de que o efeito anticompetitivo seja claramente desejado pela política regulatória desenhada para o setor. ${ }^{13}$

Em suma, mesmo com os inúmeros aperfeiçoamentos da State Action Doctrine, pode-se concluir que a imunidade antitruste tem suas raízes em teorias regulatórias desenvolvidas para reconhecer que o objetivo da regulação é justamente substituir o processo competitivo e, em decorrência

forma, um teste objetivo e consideram se a conduta que desafiou a lei antitruste foi uma consequência "previsível" da legislação para a qual é requerida autorização. ${ }^{12}$ Columbia Steel Casting Co. v. Portland General Electric Co.111 F.3d at 1427 (9th Cir. 1997), cert. denied, 523 U.S. 1112 (1998). Disponível em:

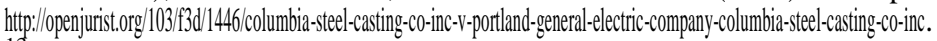

${ }^{13}$ Segundo Steven Croley (2008, p. 248), defensores da Teoria da Public Choice encontram suporte adicional na tese de que o domínio legislativo envidaria esforços para prevenir ou desencorajar as agências reguladoras de adotarem atos contrários aos interesses do Congresso. 
disso, afastar, por completo, a incidência das normas antitruste e a competência das autoridades de defesa da concorrência.

\section{State Action Doctrine e o caso VU-M}

Quando se trata da convivência entre regulação setorial e regulação geral, no caso, antitruste, três possíveis correntes podem ser apontadas atualmente. Pela primeira, a regulação setorial e a regulação antitruste seriam mutuamente excludentes, no sentido de que, na existência de uma regulação setorial, a regulação concorrencial estaria afastada de plano - tal como se via nitidamente no primeiro momento de aplicação da State Action Doctrine - que tinha como fundamento a teoria regulatória do interesse público.

A segunda corrente condiciona a atuação da autoridade antitruste à ausência de competência da agência setorial para tratar de matéria concorrencial (ou sua omissão em fazê-lo de forma eficaz) ou ainda quando há determinação legal no sentido de substituir a concorrência pela regulação. Essa corrente pode ser traduzida nos ensinamentos de Calixto Salomão Filho, de que "há isenção antitruste quando a decisão ou regulamentação é tomada em consequência de uma política claramente expressa e definida de substituição da competição pela regulamentação". (Salomão Filho 2002, p. 136)

Esclarece o autor que a imunidade nesta hipótese se justifica em razão das previsões do art. 174 da Constituição Federal do Brasil, que dispõe sobre o planejamento econômico impositivo do Estado. Pelas disposições constitucionais, a imunidade concorrencial seria admitida, se e somente se, houver previsão legal expressa no sentido de substituir a regulação concorrencial por meio da outorga de poderes ao agente regulador para influir nas variáveis fundamentais de orientação da vida empresarial (preço, quantidade produzida e entrada no mercado).

Isso significa que essa anuência deveria seguir as linhas mais restritas de incidência da isenção antitruste, no sentido de que não basta uma mera previsibilidade de efeitos da atuação do órgão regulador ou ainda de que a conduta é inerente aos objetivos perseguidos pela agência reguladora; é 
necessária uma determinação expressa do Poder Legislativo no sentido de restringir a concorrência. ${ }^{14}$

Trata-se, portanto, de uma postura mais rígida de aplicação da State Action Doctrine, em seu segundo momento - traduzida na decisão Columbia Steel -, sob influência da Teoria da Public Choice.

Já na terceira corrente, prevalece o entendimento de que há uma coexistência complementar e harmônica entre regulação setorial e regulação concorrencial, o que parece ser mais consentâneo com a legislação brasileira. Nas palavras de Marques Neto (2002, p. 95): "a regulação setorial não caracteriza um feudo, uma área livre, isenta da incidência de parâmetros de regulação geral. Os pressupostos que justificam a existência de uma regulação setorial (...) não podem excluir os pressupostos ensejadores da regulação geral". Daí concluir que não há que se falar em reservas de regulação, nem em setores imunes à regulação geral antitruste.

A própria Lei de Defesa da Concorrência, em seu art. 31, expressamente submete ao seu alcance "as pessoas físicas ou jurídicas de direito público ou privado, mesmo que exerçam atividade sob regime de monopólio legal”, ou seja, o dispositivo revela a intenção do legislador em submeter à apreciação do CADE qualquer conduta potencialmente lesiva à concorrência, mesmo se referida conduta estiver sob o controle estatal. Corrobora essa linha de entendimento as disposições da Constituição Federal que erigiram a defesa da concorrência como princípio da ordem econômica brasileira (art. 170), e, como resultado, nenhuma atividade econômica estaria imune a ela.

Essa parece ser, inclusive, a orientação do CADE sempre quando o tema do conflito de competência entre o CADE e as agências reguladoras entra em pauta na análise de preliminares ao mérito.

No caso VU-M, por exemplo, ao fazer um cotejo entre a Lei Geral de Telecomunicações e a Lei de Defesa da Concorrência, a conselheirarelatora, Ana Frazão, demonstrou claramente que o art. 19 da LGT, apesar de conferir poderes à ANATEL de controle, prevenção e repressão de

${ }^{14}$ No caso VU-M, por determinação do $\S 2^{\circ}$, art. 153 da LGT, a ANATEL poderia interferir diretamente para arbitrar o valor da tarifa VU-M. Ocorre que a lei nada menciona sobre como se deve chegar a esse valor, ou ainda, se deve haver um tratamento diferenciado para os valores de uso de rede fixa e da móvel. 
infrações no setor de telecomunicações, o mesmo dispositivo, ressalva expressamente, no inciso XIX, a competência do CADE para a defesa da ordem econômica, não obstante a ANATEL também deter prerrogativa similar. Essa previsão legal estabelece, portanto, um sistema de competência concorrente de combate às infrações à ordem econômica no referido segmento. ${ }^{15}$

Nota-se, todavia, que, apesar de as decisões do CADE serem refratárias à imunidade antitruste, certo grau de abstenção tem sido observado quando o colegiado se viu diante de situações que envolvem mercados regulados, tal como se depreende, inclusive, do recente julgamento do caso VU-M. Conforme as observações de Rocha et al. (2003, p. 240) ao fazer um balanço da jurisprudência do CADE a respeito da aplicação de imunidade antitruste a atos respaldados pela política regulatória, podem-se observar dois fenômenos:

Em primeiro lugar, parece haver um cuidado para evitar qualquer reconhecimento expresso da possibilidade de imunidade antitruste no contexto da atuação de órgãos federais. Apesar disso, e esse é o segundo fenômeno a observar, se não há aplicação, ainda que tímida, de imunidade, as decisões do colegiado não deixam, em diversos casos, de emprestar consequências, no que diz respeito à sua própria análise, à regulação setorial, como a admitir um papel regulador no que diz respeito às preocupações concorrenciais: disso decorre 0 grau de abstenção mencionado.

Uma breve e simplificada leitura do voto proferido no caso VU-M poderia levar a conclusão de que a simples existência de um ato regulatório seria suficiente por si só para afastar a subsunção da conduta do administrado ao direito concorrencial. Nos termos da decisão, "o pressuposto da existência de infração à concorrência é precisamente a existência de determinada margem de autonomia que a regulação deixe para os agentes econômicos". Isto é, não há que se falar em conduta ilícita se o

${ }^{15}$ São decisões do CADE no mesmo sentido: Processo Administrativos $\mathrm{n}^{\circ}$ 53500.005770/2002, 08012.007443/1999-17, 08012.008060/2004-85.

Revista de Direito, Estado e Telecomunicações, v. 6, n. 1, p. 127-158 (2014)

DOI: https://doi.org/10.26512/1str.v6i1.21555 
agente não possui certa margem de liberdade de comportamento que lhe permita agir de forma autônoma.

Neste aspecto, o argumento central desenvolvido no voto pode remeter à primitiva aplicação da State Action Doctrine, que, sob os fundamentos do interesse público, empregava de forma sumária isenções baseadas no mero caráter público do ato e na credibilidade da atuação do órgão regulador.

Há, igualmente, trechos da decisão que refletem os requisitos da imunidade antitruste desenvolvidos sob a influência da Public Choice, nos moldes originariamente empregados no caso Midcal, na medida em que buscava ressaltar o caráter essencialmente regulatório da questão, capaz de elidir, por si, a aplicação da legislação antitruste.

Os objetivos originais e tradicionalmente buscados pela ANATEL no que tange a tarifação do VU-M, bem como a política aplicada para o setor de telefonia como um todo, foi inúmeras vezes revisitado pelo CADE, tal como se depreende do seguinte trecho do voto:

O que se observa, portanto, é que, se existe algum problema relacionado ao VU-M, esse problema é, nas circunstâncias delineadas no presente feito, essencialmente regulatório. Se há distorções à concorrência, decorrem elas do âmago da política regulatória que vem sendo implementada pela ANATEL.

Ou ainda quando o Conselho reconhece que a fixação do valor de VU-M em patamares supostamente elevados era um propósito específico da ANATEL para manter a assimetria entre o serviço de telefonia móvel e o serviço fixo como uma forma de ampliar a base de usuários da rede móvel no Brasil. ${ }^{16} 17$

${ }^{16}$ Trecho extraído da manifestação da ANATEL a respeito da importância da tarifa VU-M: "Ademais, para o modelo regulatório escolhido e implementado no setor de telecomunicações do Brasil, o VU-M tem importância fundamental para a expansão das telecomunicações no Brasil. Nos últimos anos, a telefonia móvel vem sendo a principal responsável pela expansão das telecomunicações no Brasil, representando atualmente mais que o dobro do número de linhas fixas em operação no país, sendo que o VU-M é um importante componente na viabilização de tal expansão. A título de comparação em relação à dimensão dos negócios envolvidos, todo o investimento realizado pela GVT desde a sua criação em 1998 não correspondem sequer ao investimento de 1 mês observado na telefonia móvel em 2007. A mesma proporção é 
Desta forma, uma análise precipitada do voto, poderia sugerir que há, por parte do Conselho, uma tentativa constante de atribuir os possíveis efeitos anticompetitivos da fixação do VU-M como um resultado próprio da política regulatória empreendida pela ANATEL, sem qualquer análise mais aprofundada sobre a legalidade e as consequências do ato regulatório.

Hovenkamp (2012) adverte que esse procedimento - de utilizar tão somente a teoria da ação governamental para encerrar controvérsias no âmbito do direito da concorrência -, pode se apresentar problemático, por duas razões. Primeiro, esse procedimento não faz uma correta distinção entre o que seria uma conduta competitiva de uma conduta anticompetitiva e, portanto, não consegue visualizar a verdadeira política da agência reguladora no que diz respeito à concorrência naquele setor. Em segundo lugar, uma vez que uma disposição especial foi encontrada para autorizar uma instância específica de conduta, a mesma disposição poderia, erroneamente, ser ampliada para acobertar efeitos anticompetitivos que sequer foram pretendidos pela autoridade reguladora.

A este respeito, a decisão no caso VU-M possui particularidades que merecem destaque. Como dito anteriormente, uma leitura irrefletida do voto pode levar a conclusão de que, mais uma vez, o órgão antitruste tenha se abstido de qualquer ingerência sobre o mérito concorrencial diante do aspecto regulatório que incute a questão.

Primeiramente, quando se afirmou no voto que "não houve espaço de livre iniciativa suficiente para a configuração, ainda que em tese, de qualquer conduta anticoncorrencial”, o propósito essencial da decisão mais do que uma simples aplicação de imunidade antitruste - era eximir as partes de qualquer punição por parte do CADE, uma vez que o respaldo

observada no crescimento da base de clientes da GVT em comparação à base de clientes do serviço móvel."

${ }^{17}$ Nota-se que a ANATEL não faz qualquer referência mais específica a respeito de: (i) como a tarifa VU-M é calculada; (ii) por que é tão significativa a diferença entre o valor de uso da rede móvel e de uso da rede fixa; (iii) como este tratamento não isonômico contribui para a expansão da rede móvel; ou ainda (iv) já que o propósito é expandir a rede móvel, porque atualmente o Brasil tem somente 4 operadoras de telefonia móvel e porque as empresas de telefonia fixa não conseguem entrar de forma efetiva nesse mercado. 
público seria uma excludente de culpabilidade, já que retira a autonomia de vontade do agente. ${ }^{18}$

Em segundo lugar, ainda que a tese central tenha recaído sobre a política regulatória da ANATEL para o setor de telecomunicações, a análise do caso também avançou sobre a possível natureza abusiva da tarifa de VU-M, para concluir que as provas até então colhidas eram insuficientes para demonstrar o caráter restritivo da tarifa, uma vez que (i) o VU-M não se destina exclusivamente à remuneração da interconexão; (ii) ainda que se admitisse a livre negociação a partir de 2004, o único reajuste ocorrido desde então foi de 4,5\%, inferior à inflação; (iii) a comparação do VU-M com os preços de público das móveis é inadequada, pois, além de os resultados serem inconclusivos, não há interconexão nas chamadas intrarede; e (iv) não houve comprovação dos pressupostos específicos do price squeeze. ${ }^{19}$

Dessa forma, houve uma preocupação por parte do CADE em averiguar o mérito concorrencial da conduta e afastar os possíveis efeitos anticompetitivos, evitando os potenciais inconvenientes de um arquivamento prematuro do caso ou simplesmente embasado na teoria da ação política. Isto é, a decisão foi bastante cuidadosa em averiguar não

${ }^{18}$ Duas observações merecem ser endereçadas quanto a este argumento. Primeiro, é questionável o argumento caso se considere a responsabilidade concorrencial como uma forma de responsabilidade objetiva. Isto é, mesmo sob anuência do órgão regulador, o administrado não pode se escusar da observância da legislação concorrencial, razão pela qual sempre será responsável pelos seus atos. Por outro lado, defensores da excludente de culpabilidade devem ser cautelosos na sua aplicação para averiguar se, de fato, há "ausência de atuação autônoma do agente", o que parece não ter sido feito no caso VU-M. De qualquer forma, a insuficiência desta análise se justifica pela deficiência na própria instrução do feito e nas informações prestadas pela ANATEL a respeito do histórico e das razões para a fixação desta tarifa.

${ }^{19}$ Vale ressaltar, contudo, que a análise de efeitos restringiu-se tão somente no preço abusivo da tarifa VU-M e nos requisitos do price squeeze, não fazendo qualquer menção sobre os possíveis efeitos restritivos da tarifa - mesmo durante a fase em que a tarifa era homologada pela ANATEL - na entrada de novos agentes no mercado de SMP. Essa análise talvez fosse indispensável para afastar as preocupações concorrenciais do setor, principalmente diante de uma estrutura de mercado que, há anos, não apresenta significativas alterações, sempre marcada por um caráter oligopolista. 
somente a culpabilidade das empresas representadas, como também em se afastar deste critério para perseguir os possíveis efeitos da fixação da tarifa VU-M tal como empreendida no mercado.

A verdade é que, no presente caso, sequer foi possível afigurar a natureza da conduta investigada. O que o voto buscou ressaltar, ao final, é que a conduta não só não apresentava qualquer efeito prejudicial como também não apresentava qualquer racionalidade econômica procompetitiva. Isto é, a decisão apontou justamente uma situação em que a atuação do CADE se viu prejudicada, uma vez que a própria política da ANATEL com relação à tarifa VU-M ainda se mostra bastante obscura no que toca a seus objetivos, sua racionalidade, suas consequências e os benefícios que a fixação dessa tarifa possa trazer para o mercado de forma geral, ou seja, trata-se de uma política tão nebulosa que sequer é possível verificar se há ou não efeitos anticompetitivos ou, mesmo constatado o efeito competitivo, se este efeito é de fato perseguido por uma política macroeconômica ou se se trata tão somente de um ato regulatório direcionado ao favorecimento indevido das empresas de telefonia móvel em detrimento das empresas de telefonia fixa.

Algumas passagens da decisão deixam claro esse sentido:

"Não se discute aqui, se há ou não meios mais adequados para buscar tais objetivos de universalização ou se a utilização do VU-M para atender a tal política regulatória pode ou não trazer distorções para as empresas de STFC e mesmo para a telefonia como um todo. Afinal, ainda que a resposta para essas questões seja positiva, é inequívoco que se trata de problema eminentemente regulatório.

Faço tais objeções porque valorizo as preocupações da SDE, especialmente quando ela aponta (i) que o suposto alto custo da interconexão esteja gerando distorções, tais como a necessidade de que as pessoas tenham vários chips, a fim de que façam ligações apenas intra-rede e (ii) que o Brasil é um dos países com as mais altas tarifas de telefonia celular do mundo, sendo que diferentes estudos apontam o VUM como a principal causa de tal situação. (...)

(...) é extremamente complexo se avaliar a adequação ou não da política regulatória que privilegia, no seu cálculo, 0 atendimento de políticas regulatórias de expansão e universalização da telefonia móvel.

(...) 
Por essa razão, o simples fato de 0 valor do VU-M ser superior ao da TU-RL ou dos preços de público praticados pelas móveis não é parâmetro seguro para a comprovação da abusividade. Por outro lado, inexistem dados minimamente convincentes nos autos a respeito do adequado valor do VU-M."

Nestas circunstâncias, diante da assimetria de informações sobre o setor de telecomunicações entre o CADE e a ANATEL e de um cenário altamente incerto criado pela própria política da agência reguladora, não restava a autoridade antitruste outra medida se não arquivar o feito.

De toda sorte, ainda que louvável a tentativa do CADE de afastar a potencialidade lesiva da conduta investigada no caso VU-M, há um entendimento consolidado por parte do próprio órgão de que a ele não compete revisar atos regulatórios da ANATEL. Quando muito, o CADE pode proferir uma recomendação de adequação do ato aos ditames da Lei $n^{\circ}$ $12.529 / 2011$.

Consequentemente, uma excessiva deferência à tradicional estrutura regulatória pode sobrecarregar o Estado com imunidades involuntárias, agravar situações claramente marcadas por lesões à concorrência e favorecer indústrias reguladas em detrimento de potenciais concorrentes, novos entrantes e, até mesmo, o consumidor final. Até porque, como largamente apontado pelas críticas às teorias regulatórias do interesse público e do public choice, as agências reguladoras são geralmente capturadas por grupos de interesses organizados.

É neste contexto, portanto, que o movimento de desregulação do setor de telecomunicações se apresenta como um substrato fático relevante para alterar, inclusive, a corriqueira relação que se vê entre regulação setorial e regulação concorrencial naquele setor.

\section{State Action e a desregulação do setor de telecomunicações}

Desregulação (deregulation) é um movimento que se iniciou nos Estados Unidos na década de 1970 e significou um processo de retração da regulação em setores em que o controle da atividade econômica se mostrava cada vez mais prejudicial à concorrência. Trata-se de reformas que incluem não apenas a flexibilização ou retirada de controles regulatórios do governo 
sobre o comportamento das empresas, mas a liberalização da entrada no mercado e, na maioria dos países, ainda a privatização de ativos estatais (Horwitz, 1998).

$\mathrm{O}$ setor de telecomunicações foi o primeiro a experimentar o processo de desregulação nos Estados Unidos. Até 1960, a empresa norte-americana de telefonia, AT\&T, prestava serviços em regime de monopólio regulado. Essa prestação era viabilizada por meio de subsídios cruzados com ligações locais. Posteriormente, com o aprimoramento da tecnologia de transmissão de chamadas com o surgimento das microondas, a AT\&T verificou intenso abalo nas suas estruturas comerciais, tanto que até 1969 a utilização de transmissão por microondas era ilegal, para evitar a perda de mercado por parte da empresa monopolista. No entanto, nesse mesmo ano, a MCI requereu permissão para a prestação desse serviço interconectando à rede local, o que foi, inicialmente, negado, mas, em seguida, reconhecido e concedido pela Justiça. Foi, portanto, um largo passo no processo de desregulação em um momento em que a entrada nesse mercado ainda era restrita e controlada rigorosamente pelo Estado (Peltzman, 2004, p. 111). A desregulação implica, portanto, um movimento de liberalização dos mercados.

Contrário ao que o termo sugere, desregulação não é diametralmente oposta à regulação. Trata-se, na verdade, de um movimento que não afasta a atuação governamental, mas que impõe ao órgão regulador o dever de tomar medidas que possam restabelecer a concorrência em mercados tradicionalmente marcados por monopólios.

Além disso, há um reconhecimento de que o próprio governo apresenta falhas - geralmente apontadas pelas críticas às teorias regulatórias - e que, para endereçar essas falhas, deve-se promover a concorrência a fim de se realizar os próprios objetivos da regulação. Isso significa que o regulador deve atuar em favor da concorrência, basicamente evitando restrição regulamentar e arbitrária de serviços.

Da mesma forma, a regulação deve ser compreendida como uma forma de tutela conjuntural, e não estrutural (legalista), na medida em que deve ser flexível diante das reais necessidades do mercado, principalmente no que tange a difusão de tecnologia no setor de telecomunicações. Como visto, o movimento foi deflagrado nos Estados Unidos justamente como uma 
resposta à revolução tecnológica sofrida pelo setor (Horwitz, 1989, p. 5), ou seja, como uma necessidade de se abrir o mercado para a entrada de novas tecnologias, bem como, para o desenvolvimento e expansão, a nível global, de tecnologias de redes empregadas no setor. Desta forma, conforme observado por Horwitz (1989, p. 6), a Era da Informação não só causou o movimento de desregulação como também justifica a sua continuidade.

Daí concluir que, na medida em que o processo tem por propósito reduzir as barreiras à entrada nos mercados, para que a desregulação seja eficaz, deve-se dar maior atenção a problemas concernentes a infrações ao direito da concorrência, notadamente o risco de tratamento discriminatório no acesso a insumos essenciais a prestação do serviço de telefonia.

No que toca a própria tarifa de interconexão, a Nota Técnica do DEE, emitida nos autos do processo VU-M, parte da premissa de que a interconexão é uma importante variável competitiva do mercado de telefonia, e que, exatamente por isso, "a política de interconexão deveria permitir a entrada de firmas eficientes e a saída das ineficientes, permitir que o detentor dos "gargalos" obtivesse remuneração satisfatória, mas sem excluir rivais do acesso à sua rede, e possibilitar o uso eficiente das redes". Neste sentido, a abertura dos mercados de telecomunicações para o acesso ao mercado de telefonia móvel, na medida em que são regulados concorrencialmente, conduz à variedade de serviços ofertados, à potencial redução dos preços e a serviços de melhor qualidade, o que, notadamente atenderia ao interesse público geral já que o Brasil apresenta péssima qualidade na prestação do serviço de telefonia, além de ser um dos serviços mais caros em comparação com países que apresentam estruturas de mercado semelhantes.

Justamente em razão da importância de variáveis como esta é que se desenvolve o censo crítico dos efeitos da aplicação indiscriminada da teoria da ação política em um ambiente desregulado, o que levaria a muita confusão e a um empoderamento arbitrário das agências reguladoras. Além disso, mesmo diante da abertura de mercados anteriormente regulados, a entrada de novos players neste segmento ainda ficaria sob autorização da agência reguladora, não havendo qualquer incentivo para romper com as tradicionais estruturas regulatórias oligopolizadas, tal como ocorre no setor de telecomunicações brasileiro. 
No caso VU-M, por exemplo, essa preocupação é ainda mais evidente diante das constatações da Procuradoria do CADE de que, "na verdade, tudo está a indicar que as representadas valeram-se da estrutura regulatória existente, que não apenas permitiu como referendou o valor do VU-M em patamares supostamente elevados" ${ }^{20}$, e estariam se valendo desse jogo de poderes para prejudicar a entrada de novos agentes no mercado de telefonia móvel.

Ou também diante de considerações de outra ordem de "(i) a conveniência e a adequação de submeter a questão da interconexão à regulação, já que há opiniões no sentido de que o modelo de livre negociação traz inúmeras vantagens e (ii) a própria adequação de modelos de custo para a remuneração da interconexão", tal como reconhecido pelo próprio CADE no julgamento do caso VU-M.

Em suma, o movimento de desregulação dedica-se a possibilitar uma efetiva concorrência como valor mínimo a ser garantido pelas agências reguladoras para encorajar o desenvolvimento de mercados minimamente viáveis, o que requer uma aplicação ativa dos princípios concorrenciais.

Refere-se, deste modo, a um processo de "desregulação regulada", o qual, contrariamente à auto-regulação, impõe uma atuação do Estado no sentido de viabilizar a concorrência por meio de regras comportamentais e estruturais, na medida em que garantem um relacionamento equânime e leal entre os agentes econômicos (Salomão Filho, 2008, p. 40).

Ocorre que, neste cenário, com a excessiva consideração da capacidade da agência, se houver conduta anticoncorrencial questionável a partir de uma medida regulatória adotada, questiona-se se a agência dispõe de um processo de constante revisão da conduta autorizada para afastar os efeitos anticompetitivos não visualizados no momento da concessão?

É diante desta indagação que o presente ensaio procura oferecer três formas de abordagem que podem ser aplicadas à dinâmica de interação entre regulação concorrencial e a regulação setorial, a ponto de permitir que a tradicional estrutura de aplicação das normas de concorrência a estes

${ }^{20}$ Brasil. Procuradoria Federal. Parecer $n^{\circ}$ 68, de 12 de março de 2013. Disponível em: http://www.cade.gov.br/temp/D_D000000728651753.pdf. Acessado em 5 de outubro de 2013.

Revista de Direito, Estado e Telecomunicações, v. 6, n. 1, p. 127-158 (2014)

DOI: https://doi.org/10.26512/lstr.v6i1.21555 
setores possa ser redesenhada para incorporar, além dos objetivos perseguidos pelo movimento de desregulação, também objetivos de promoção da concorrência, que permeia necessariamente todos os setores regulados.

A primeira delas recai sobre a própria configuração da infração concorrencial sob o aspecto da conformação da responsabilidade do administrado a partir da análise do elemento volitivo da conduta investigada. Uma interpretação estrita do art. 36 da Lei 12.529/2011 sugere que a responsabilidade concorrencial é "independente de culpa", e, desta previsão, poderia cogitar-se sobre a responsabilidade concorrencial objetiva, o que dispensaria, para sua ocorrência, qualquer aferição da intencionalidade do agente ou da valoração da conduta a ele imputada, bastando, para a caracterização da infração, apenas a existência do potencial lesivo da conduta.

Trata-se, portanto, de uma proposta contrária à tese central desenvolvida no julgamento do caso VU-M, segundo a qual o respaldo regulatório seria uma excludente da culpabilidade do infrator. Por meio desta primeira abordagem, constatado o potencial lesivo da prática investigada, ele atrairia de plano a responsabilidade do agente e a incidência do direito antitruste, inclusive, para a aplicação de multas e outras penalidades.

Outra forma de abordagem - mais compatível com a responsabilidade concorrencial subjetiva - é a possibilidade de a autoridade antitruste atuar no sentido de afastar a conduta anticompetitiva, ainda que amparada por ato regulatório, sem a imposição de qualquer pena ao administrado. ${ }^{21}$ Trata-se de uma proposta de direito administrativo infracional em substituição ao direito administrativo sancionador, em que o CADE, no exercício de sua competência de promoção da concorrência e de proteção da higidez da ordem econômica (art. $9^{\circ}$, da Lei 12.529/2011), não apenas recomenda à ANATEL que promova a adequação do seu ato aos ditames da lei de defesa da concorrência - aos quais já deveria estar adstrita nos termos do art. 127, III da LGT -, como também determinar medidas necessárias a promoção da concorrência e a cessação de condutas anticompetitivas - tal como disposto

${ }^{21}$ Hipótese em que não se admite a responsabilidade concorrencial objetiva. 
nos arts. 39 e 84 da Lei 12.529/2011 -, ainda que tais medidas sejam contrárias a política até então implementada pela agência reguladora.

Seria, desta forma, uma proposta intermediária, que possibilitaria a atuação da autoridade antitruste no sentido de afastar os problemas concorrenciais sem que isso implicasse em medidas injustas para o administrado que atuava no estrito cumprimento de um ato regulatório.

Por fim - e a mais radical delas - seria a possibilidade de atuação mais ampla por parte da autoridade antitruste no sentido de interferir na atividade do agente econômico quando sequer é possível aferir a potencialidade anticompetitiva da conduta sempre que a política regulatória do setor se mostrar um obstáculo para essa análise, isto é, quando se mostrar incerta e obscura quanto às consequências e aos reais objetivos pretendidos para aquele mercado.

Por um lado, conferir amplos poderes à autoridade concorrencial poderia ser uma forma de alcançar efetivamente a desregulação do setor e romper com a tradicional estrutura corrompida das agências reguladoras, a fim de evitar os tradicionais problemas da captura e do favorecimento de grupos empresariais organizados.

Por outro lado, o excesso de competência do CADE poderia torná-lo revisor de políticas regulatórias, o que lhe possibilitaria, inclusive, avaliar a necessidade e a conveniência dos atos da administração pública que possam eventualmente ter efeitos sobre o ambiente concorrencial, tolhendo, assim, a autonomia das agências reguladoras. Dessa forma, retomamos à velha questão de que a interação entre agencia setorial e concorrencial são atuações complementares e não sobrepostas, o que não impede, contudo, que esta tese ousada venha a ser refinada para se adaptar a esse modelo de interação.

\section{Conclusões}

Verificou-se, em razão da experiência do CADE, que este órgão não intervém efetivamente em mercados regulados, havendo ainda espaço para adjudicação da lei antitruste em razão de que as decisões fundamentais de orientação da ordem econômica já foram tomadas na esfera regulatória. 
Diversamente do que vinha se observando, a análise empreendida pelo Conselho no julgamento do caso VU-M, mesmo centrada na questão regulatória, procurou se debruçar - e o fez satisfatoriamente - sobre o mérito antitruste da controvérsia, para entender que, mesmo diante do respaldo regulatório, não restou comprovado nos autos a ocorrência de qualquer efeito prejudicial à concorrência por circunstâncias fáticas outras que, por si, afastavam o potencial lesivo da conduta.

Não obstante, a análise do caso revelou que ainda persiste o tradicional trade-off entre regulação econômica setorial - especialmente quanto à definição de preços - e defesa da concorrência. Em outros termos, a tese central desenvolvida no caso ainda sugere que quanto maior o controle estatal de variáveis econômicas fundamentais, menor será o espaço para a liberdade de iniciativa e concorrência, e, consequentemente, menor será a possibilidade de intervenção antitruste.

Ocorre que a solução pode não estar necessariamente em conformidade com a nova política regulatória para o setor regulado, principalmente naqueles marcados pelo processo de desregulação, como 0 de telecomunicações.

Como visto, a concessão de imunidades concorrenciais pode criar um ambiente de extrema confiança na atuação da agência reguladora na promoção da concorrência em favor do processo de desregulação, o que, historicamente não ocorreu no setor, já que tradicionalmente foi marcado por excessiva regulação restritiva da concorrência.

Assim, a partir das propostas apresentadas, o trabalho buscou oferecer uma abordagem introdutória que possa ser aplicada posteriormente para rediscutir os limites de aplicação da lei de defesa da concorrência a situações acobertadas por medidas regulatórias setoriais, a fim de melhor atender aos propósitos de desregulação e promoção da concorrência no setor de telecomunicações, uma análise que será reservada a trabalhos futuros. 


\section{Bibliografia}

CHIN, Yee Wah. Administrative Monopoly:The State Action Doctrine under U.S. Antitrust Law. Traduzido de Wang, Xiaoye (org.). "Hot Spots of Chinese Antimonopoly Legislation". Social Sciences Academic Press 2007, p. 127-140. Disponível em: htpp://papers.ssn.com/sol3/papers.cfm?abstract_id=1621067. Acessado em 5 de outubro de 2013.

CROLEY, Steven P. Regulation and Public Interests. Princeton: Princeton University Press, 2008.

DELACOURT, John T. e ZYWICKI, Todd J. The FTC and State Action: Evolving Views on the Proper Role of Government. George Mason University School of Law (PERC - Property and Environment Research Center). In: Antitrust Law Journal, vol. 72, n. 3, p. 1075-1090, 2005. Disponível em: htpp|//papers.ssnn.com/s013/papers.cfm?abstract_id:695541. Acessado em 5 de outubro de 2013.

HORWITZ, Robert Britt. The irony of regulatory reform: the deregulation of American telecommunications. New York/Oxford: Oxford University Press, 1989.

. Deregulation as a Political Process. In: Exitos y Fracasos de

la Nueva Regulación en Telecommunicaciones (Conference). Centro de Investigación y Docencia Económicas (CIDE). Cidade do México, março de 1998.

HOVENKAMP, Herbert J. Antitrust's State Action Doctrine and the Ordinary Powers of Corporations. University of Iowa (College of Law Iowa Legal Studies Research Paper No. 12-30), 12 de julho de 2012. Disponível em: http:///appers.ssn.com/sol3/papers.cfm?abstract_id:2012717. Acessado em 5 de outubro de 2013.

PELTZMAN, S. A teoria econômica da regulação depois de uma década de desregulação. In: MATTOS, Paulo (org.). Regulação econômica e democracia: o debate norte- americano. São Paulo: Editora 34, 2004.

POSNER, Richard A. Theory of economic regulation. Center for Economic Analysis of Human Behavior and Social Institutions. National Bureau of 
Economic Research. New York, maio de 1974. Disponível em: http://www.nber.orgepapers/w0041.pdf?!new_window=1. Acessado em 5 de outubro de 2013.

ROCHA, Bolívar Mora e OLIVEIRA, Hermes Nereu Cardoso. Balanço da Articulação entre Órgãos de Defesa da Concorrência e Agências Reguladoras de Infraestrutura. In: A Regulação da Infra-Estrutura no Brasil. coord. Bolívar Moura Rocha, IOB, São Paulo, 2003.

SCHOLZE, Simone. A retomada dos esforços de P\&D nas telecomunicações brasileiras: uma perspectiva das teorias regulatórias. Revista de Direito, Estado e Telecomunicações 5(1): 107-134, 2013.

SUNDFELD, Carlos Ari. Concorrência e Regulação no Sistema Financeiro. In: Concorrência e Regulação no Sistema Financeiro. Max Limonad. São Paulo, 2002.

TRUJILLO, Elizabeth. State Action Antitrust Exemption Collides with Deregulation: Rehabilitating the Foreseeability Doctrine. In: Fordham Journal of Corporate and Financial Law 11(2): 349, 2006. Disponível

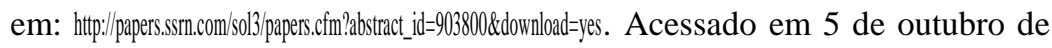
2013.

SEMERARO, Steven. Demystifying Antitrust State Action Doctrine. In: Harvard Journal of Law and Public Policy 24(1): 203, 2000. TJSL Legal Studies Research Paper No. 1120002. Disponível em: http://papers.ssn.com/s013/papers._fm?abstract_id=1120002. Acessado em 5 de outubro de 2013.

\section{Ementa do Caso VU-M}

Conselho Administrativo de Defesa Econômica. Processo Administrativo instaurado para apurar (i) possível prática exclusionária por meio da elevação dos custos de rivais no mercado brasileiro de telefonia e (ii) possível conluio entre concorrentes na fixação do Valor de Remuneração do Uso da Rede Móvel (VU-M), passíveis de passíveis de enquadramento nos incisos I, II, III e IV do art. 20, c/c incisos I e V do art. 21 da Lei 8.884/94. Parecer da SDE e do MPF pela condenação dos Representados Vivo, Tim e Claro pela prática de conduta 
exclusionária e pelo arquivamento nos demais pontos. Parecer da ProCADE pelo arquivamento do processo em relação a todas as Representadas em todos os pontos. Inexistência de elementos configuradores da prática exclusionária ou do conluio. Voto pelo arquivamento do processo. PA n ${ }^{0}$ 08012.008501/2007-91. Representante: Global Village Telecom Ltda., Intelig Telecomunicações Ltda., Transit do Brasil Ltda. e Easytone Telecomunicações Ltda. Representadas: Americel S.A, Claro S.A, Tim Brasil Serviços e Participações S.A, TNL PCS S.A e Vivo S.A. Conselheira-Relatora: Ana Frazão. Brasília, 11 de setembro de 2013.

Disponível em: http://www.cade.gov.br/temp/D_D000000756991033.pdf. 